\title{
ARGELIA Y LOS ESTUDIOS ÁRABES EN ALICANTE (I): MÍKEL DE EPALZA
}

\author{
FranCISCO FRANCO-SÁNCHEZ \\ Universidad de Alicante
}

En el presente estudio deseamos presentar los trabajos elaborados por Míkel de Epalza en torno a Argelia, y en especial sobre el estudio de la historia argelina y española. De igual modo, este trabajo busca ser un modesto homenaje a todos los investigadores que han trabajado sobre nuestra historia común, argelinos, españoles y de cualquier otro origen, $y$ en especial a quienes publicaron sus investigaciones en Argelia tras su independencia en 1962, que Míkel de Epalza ya estudiara hasta la fecha del año 1973, y cuyo elenco y conclusiones publicó como un libro titulado de Écrits relatifs à l'bistoire de l'Espagne publiés en Algérie de 1962 à 1973. ${ }^{1}$

Las líneas esenciales de este estudio nacen de nuestro trabajo junto a Míkel de Epalza durante largos años y de la ponencia que presentamos al Congreso que en homenaje a Mouloud Kassem se celebró en Argel, entre el 27-29 de marzo de 2005. ${ }^{2}$

${ }^{1}$ Editado en Argel: ed. S.N.E.D. - Publications de la Bibliothèque Nationale (collection Bibliographie et Catalogues, vol. 3), 1976 (e igualmente en Túnez, en francés, 1975-1976, y en Barcelona, en español, Índice Histórico Español, 1965).

${ }^{2}$ En recuerdo de su memoria y en homenaje a la importancia de su personalidad, el Alto Consejo Islámico de Argelia (HCI, Al-Machlis al-Islamī lA'là), organismo oficial dependiente de la Presidencia de la República (Ri'āsa al-Chumburiyya), organizó un encuentro y coloquio los días 27, 28 y 29 de marzo en Argel. Al Multaqà Mawlūd Qūsim Naìt Bilqāsim acudieron las más notables personalidades que le conocieron, tanto de la política, como de la cultura y de las más altas instancias religiosas del país. Organizado por el Dr. Bouamrane Cheikh, Presidente del Alto Consejo Islámico y bajo los auspicios de la Presidencia de la República, acogidos en el confortable y amplio 
Lo que presentamos aquí es una redacción más completa y específica sobre la labor y los trabajos que Míkel de Epalza dedicó al estudio de Argelia, que busca dar a conocer tanto su personalidad como algunos de los estudios bibliográficos que sobre Argelia y España se han realizado en los últimos 50 años. ${ }^{3}$ Deseamos que sirva este estudio como homenaje a la labor aperturista de Mouloud Kassem, así como a la memoria de su predecesor en el Ministerio de Asuntos Religiosos, el Ministro Ahmad Taoufic Al-Madani, autor de una obra fundamental titulada Harb thalāthumi'a sana bayna Al-Jazā'ir wa-Isbāniyā (14921792) ${ }^{4}$, a quien Míkel dedicó un estudio en 2001. ${ }^{5}$

hotel El-Aurassi de Argel, se celebraron estas jornadas de homenaje a la figura y significación del que fuera Ministro de Asuntos Religiosos y luego responsable del Alto Consejo para la Lengua Árabe. El volumen de las actas del encuentro ha aparecido recientemente con el título Al-Multaqà l-Watanī li-takrìm al-mufakkir al-marḥūm li-l-Ustād Mawlūd Qāsim Nāyt Bilqāsim, ayyām 17, 18, 19 șafar 1426 H./ 27, 28, 29 mars 2005 M., Argel: ed. al-Maŷlis al-Islāmī al-' Ālà. Nuestro estudio apareció en el vol. 2, 2006, pp. 211228.

${ }^{3}$ Hicimos una reseña del citado congreso: «Congreso-Homenaje a Mouloud Kassem (Multaqà Watani li-takrim al-munadil wa-l-mufakkir al-marhum Mawlud Qasim Nait Bilqasim), Argel, 27-29 de marzo de 2005», Awrāq, Madrid, ed. Dirección General de Relaciones Culturales y Científicas de la Agencia Española de Cooperación Internacional, vol. XXII, 2001-2005, pp. 491-494.

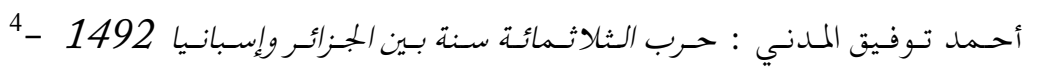

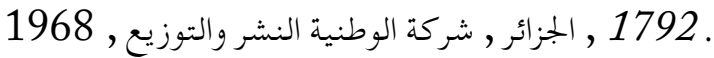

${ }^{5}$ Véase su artículo: «Tres historiadores y políticos de Argelia presentan la política de Carlos $\mathrm{V}$ con la naciente Argelia moderna: Az-Zahhar (m. 1872), Zavala (1886) y Al-Mádani (m. 1983)» en la obra colectiva coordinada por María Jesús Rubiera, Carlos V, los moriscos y el Islam, Madrid, Sociedad Estatal para la Conmemoración de los Centenarios de Felipe II y Carlos V / Universidad de Alicante, 2001, pp. 233-267. 
I. LAS GRANDES LÍNEAS DE LAS PUBLICACIONES ARGELINAS SOBRE HISTORIA Y CULTURA ESPAÑOLAS, DESPUÉS DE LA INDEPENDENCIA

Estas grandes líneas de publicaciones fueron definidas por Míkel de Epalza en su importante estudio titulado Écrits relatifs à l'histoire de l'Espagne publiés en Algérie de 1962 à 1973. En esta obra, esencial para conocer la bibliografía científica sobre las relaciones argelino-españolas, pueden encontrarse un total de 71 referencias bibliográficas en lengua árabe, así como 119 referencias diversas en lenguas europeas, en especial en francés. Este repertorio bibliográfico, que incluye algunos juicios de valor y una introducción, muestra realmente todo lo publicado por argelinos y extranjeros en Argelia hasta la fecha (1973), así como todo lo publicado por argelinos en el extranjero.

Este repertorio está dividido en seis partes, a saber: Obras generales que tratan de las relaciones argelino-españolas; Estudios sobre la antigüedad preislámica; Edad Media; Siglos XVI al XVIII; Época moderna: siglos XIX-XX, acabando con unas conclusiones generales. Pasamos a analizar cada uno de los capítulos de la obra, comentando las más importantes referencias bibliográficas de cada período:

1. El primer capítulo ${ }^{6}$ trata sobre las obras generales, y en él se comienza resaltando la labor editora de la Bibliothèque Nationale de Argel, y no únicamente por el mantenimiento de la lista de las obras del Depósito Legal, sino especialmente por su línea regular de ediciones. Entre ellas cabe destacar la compilación bibliográfica sobre el pensamiento islámico, editada con ocasión del Année International du Livre, en la que se incluye una lista de obras de autores y de materias españolas que en ese momento estaban en la Bibliothèque Nationale d'Alger. ${ }^{7}$

${ }^{6}$ Cf. Míkel de Epalza, Écrits relatifs à l'histoire de l'Espagne, pp. 9-12.

${ }^{7}$ Année Internationale du Livre. La Pensée musulmane à travers les écrits d'Orient et d'Occident, Argel, Bibliothèque Nationale, 1972/1392. 
En un segundo lugar, se repasan las revistas que incluían artículos referentes a la historia de España. Las principales revistas argelinas de los años 70 eran la Revue d'Histoire et Civilisation du Maghreb, publicada por la Société Historique (heredera de la centenaria Revue Africaine y de los Annales de l'Institut d'Études Orientales); Lybica, del Centre de Recherches Anthropologiques, Préhistoriques et Ethnographiques (C.R.A.P.E.); Ath-Thaqāfa, del Ministère de l'Information et de la Culture; Al-Asāla, del Ministère de l'Enseignement Originel et des Affaires Religieuses, y Archives Nationales, de la Présidence. Habría que añadir algunos volúmenes de actas y de comunicaciones a congresos de tipo histórico, así como ciertas obras generales sobre la civilización islámica en las que se encuentran referencias obligadas al esplendor del período hispano-musulmán medieval.

Entre las obras generales, hallaremos especialmente algunas sobre la tradición árabe andalusí. ${ }^{8}$ A ellas que hay que añadir los textos escolares, que ejercen una gran influencia sobre el conocimiento de la historia entre los alumnos, mucho más que la prensa o que las obras de los especialistas. En su mayor parte conceden mucha importancia al período de la historia de alAndalus. Míkel de Epalza ha mostrado la importancia del estudio escolar de la historia hispano-árabe en los libros de texto de Siria y también de Argelia. ${ }^{9}$

Las obras generales de historia de Argelia consagran numerosas páginas a las relaciones argelino-españolas. Desde el punto de vista de la información hispánica que ofrecen, su propor-

${ }^{8}$ M. Mure Bencheikh, «Présentation de travaux sur la tradition araboandalouse», Cahiers Algériens de Littérature Comparée, Argel, 1968, núm. 3, pp. 159-171.

${ }^{9}$ Míkel de Epalza, «España y su historia vista por los árabes actuales (A partir de los textos de enseñanza media de Siria)», Almenara, Madrid, Universidad Autónoma de Madrid, 1972, núm. 2, pp. 51-108. 
ción se corresponde con el conjunto de la producción argelina en este tema.

2. Sobre las relaciones que pudieron existir entre las dos orillas del Mediterráneo occidental, desde la Prehistoria a la conquista islámica no había prácticamente nada escrito ${ }^{10}$. Este período estaba cubierto por numerosas publicaciones, realizadas sobre todo por extranjeros que se interesaban por las diversas regiones del Magreb antiguo y por lo que actualmente es Argelia. Sobre la historia de España, casi nada. Tampoco se hallarán muchos más estudios que se refieran al Norte de África en publicaciones contemporáneas españolas.

En esta época antigua parece que se establece una diferencia, un corte entre las respectivas historiografías de este período, que propició muchas ocasiones de relación y de historia en común. Se puede atribuir esta perspectiva a la escasa familiaridad con la bibliografía no francesa, como lo muestran claramente los repertorios bibliográficos sistemáticos realizados sobre el período ${ }^{11}$. Sobre la época romana, se hallan únicamente algunas referencias en algunos artículos que muestran las numerosas corrientes políticas, culturales y personales que debieron establecerse entre las dos regiones del imperio. Nada acerca de las relaciones hispano-magrebíes en el período bizantino y vándalo.

3. En cuanto llegamos a la Edad Media islámica, la producción argelina que trata sobre la historia de la Península Ibérica, y más concretamente sobre España es, naturalmente, más abundante. Los dos países se hallan unidos bajo una misma cultura

${ }^{10}$ Cf. Écrits relatifs à l'histoire de l'Espagne, pp.13-14.

${ }^{11}$ S. Lancel; J. Desanges, «Bibliographie analytique de l'Afrique antique», Bulletin d'Archéologie Algérienne, Alger, no I, 1962-1965, pp. 277-301; $\mathrm{n}^{\circ}$ II, 1966-1967, pp. 315-341; no III, 1968, pp. 393-430. 
árabe e islámica, circunstancia esencial que define la esencia de la Argelia presente y que se reconoce como vector esencial de la Argelia del pasado ${ }^{12}$.

Especial consideración se ha prestado al estudio sobre alAndalus, siendo considerado como un faro de civilización para Europa y el Magreb. Sobre los primeros años de la conquista, así como sobre los primeros siglos del gobierno islámico en el Magreb y al-Andalus encontramos diversos estudios: de H. R. Idris, C. Camilleri, M. Talbi, M. Barbour, T. Lewicki, A. T. Madani y M Laqbal.

Es igualmente importante citar los numerosos artículos que han versado sobre los viajeros y geógrafos andalusíes, en especial sobre Ibn Sa'īd al-Magribī, el valenciano al-'Abdarī, y otros, como los trabajos de M. Belgrad y R. Bounar sobre andalusíes de paso por Bujía, en donde luego se establecerían, publicados en la revista $A l-A$ sala.

Propiamente sobre la historia de al-Andalus encontramos el importante trabajo de $\mathrm{H}$. Terrasse sobre los reinos de taifas, así como otros de J. P. Riocreux y de Ch. E, Dufourcq. Sobre la época almohade están los de Y. Bouabba y R. Bourouibba sobre Ibn Tumart en Bujía, así como otro de A. Djilali sobre la lucha emprendida por los almorávides contra el incipiente movimiento almohade.

Más relevantes son los trabajos sobre la historia literaria de esta época, por más que sean poco abundantes, que trataban sobre al-Mu'tamid Ibn 'Abbād, el rey poeta de Sevilla, los valencianos Ibn al-Abbār y el poeta Ibn Jafâŷa, etc. Esta brillante etapa de la literatura hispano-árabe está, por tanto, bien representada en la producción argelina anterior al año 1976.

De igual modo, la historia cultual del período medieval está centrada sobre el interés hacia la filosofía árabe andalusí, en concreto sobre las figuras de Ibn Tufayl, al-Gazālī, a los que hay

${ }^{12}$ Cf. Écrits relatifs à l'histoire de l'Espagne, pp. 15-19. 
que añadir la tesis de M. Talbi sobre los problemas del lenguaje según el andalusí Abū Bakr Ibn al-'Arabī.

Para la Edad Media las fuentes hispánicas ciertamente son más abundantes, en especial gracias a los espléndidos fondos del Archivo de la Corona de Aragón en Barcelona, cuya riqueza documental para la historia del Magreb ha sido adecuadamente presentada por F. Udina, y especialmente por Ch. E. Dufourcq, N. E. Gais y A. Dhina.

Otras figuras han recibido la atención de los especialistas, tales como la de Raimon Llull, y sobre todo la del polígrafo magrebí Ibn Jaldūn, y también la del granadino Ibn al-Jaṭīb.

Contrastando con otros períodos históricos precedentes y posteriores, podría dedicarse un capítulo especial a los estudios sobre la arqueología medieval argelina (en el que las relaciones con al-Andalus se hacen evidentes), habiendo de incluir también otros estudios sobre el arte religioso musulmán en Argelia, sus relaciones con el arte andalusí, los museos, etc.

4. Una importancia rayana en lo mítico es la que conceden estas publicaciones al enfrentamiento hispano-turco, y especialmente, hispano-magrebí a partir del siglo XVI. A partir de esta época se establece definitivamente el espacio político argelino, y nace la actual Argel, como un núcleo de resistencia secular a la política militar española en el Mediterráneo occidental ${ }^{13}$.

Esta es una época muy importante para la historia de Argelia y para su historiografía moderna, dado que en ella se tiende a ubicar el origen de Argelia. Así, en el marco de una ideología militante hay que ubicar la obra magistral del embajador y ex ministro A. T. Madani "Guerre de trois cent ans entre l'Algérie et l'Espagne». Los estudios, como los de M. Bordj o Y. Bouabba, presentan esta época como una lucha hispano-turca en el $\mathrm{Me}$ diterráneo, en el que los argelinos están del lado de sus aliados

${ }^{13}$ Cf. Écrits relatifs à l'bistoire de l'Espagne, pp. 21-23. 
musulmanes, los turcos. En la mayor parte de las historias se presenta la presencia turca en Argelia como una alianza que suponía obligaciones de parte argelina, pero que no suprimía la independencia o una relativa autonomía de la "regencia". Todas las historias de Argel presentan el nacimiento de esta capital como un acto de resistencia victoriosa contra el emperador y Rey de España Carlos V. De este modo, las expediciones de Carlos $\mathrm{V}$ fueron objeto de especial atención por parte de la investigación.

Otros estudios se fijaron en el descubrimiento de América, el nombre de Brasil, el personaje de origen granadino que luego fue conocido como León el Africano, las relaciones entre los dirigentes de la Kabilya con los reyes de España, etc. Por el contrario, la llegada de los andalusíes expulsados de España (los moriscos) o el estudio de su instalación habían recibido una atención muy escasa, a pesar de la importancia del aporte demográfico a Argelia que supuso la inmigración de estos musulmanes de origen español.

Los diferentes tratados de paz hispano-argelinos no habían sido suficientemente estudiados aún y M. de Epalza señala esta falta. Él mismo posteriormente estudiará varios de estos tratados.

5. Se puede considerar que la época contemporánea de la historia de Argelia comienza con la ocupación francesa de $1830 .{ }^{14}$ Es necesario subrayar que los trabajos que muestran la opinión política de los diplomáticos españoles respecto a la ocupación no son ni numerosos ni importantes, y muestran a una España más ocupada por sus guerras civiles y por la liquidación de su imperio americano. Por el contrario, dos pequeños trabajos sobre el Emir Abdelkáder tienen que ver con aspectos españoles de su

${ }^{14}$ Ibid., pp. 25-27. 
vida: una bibliografía (que le consagró $\mathrm{M}$. Bouayed) y el estudio de la actividad diplomática de su hijo en Madrid (por A. Saadallah).

Sobre el siglo XX colonial no hay apenas nada que señalar. Este desinterés por la historia española es aún más evidente en el libro de Kh. Mameri, en el que se analiza la posición de España en la ONU, frente al problema argelino, postura verdaderamente difícil y original ${ }^{15}$.

Los estudios etnológicos raramente se remontan a las tradiciones andalusíes o españolas en Argelia. Pero en el ámbito de las artes o de las letras la producción argelina sobre tema español es mucho más abundante. Así, diversos trabajos universitarios han sido consagrados a la literatura española, en el marco de la Licence d'Espagnol de la Faculté des Lettres de Argel y en la de Orán, del mismo modo que una serie de estudios sobre literatura comparada fueron publicados en la revista Cabiers $\mathrm{Al}$ gériennes de Littérature Comparée. Y esto es prácticamente todo.

6. Como colofón de este estado de la cuestión, subraya el autor que no pueden extraerse demasiadas conclusiones de este balance bibliográfico. No obstante, se imponen algunas reflexiones generales, que habría que situar en el 1976 en que se publicó la compilación.

En primer lugar, es necesario anotar la falta general de investigadores en la época, circunstancia que afectaba a todos los sectores de la investigación histórica en Argelia. A pesar de esta circunstancia general, en el ámbito que nos concierne, la situación se fue mejorando, con fulgurantes progresos tras la independencia y como consecuencia de la multiplicación de los trabajos de investigación hechos por los universitarios.

Para acabar, se subraya que el obstáculo lingüístico es igual-

${ }^{15}$ Kh. Mameri, Les Nations unies face à la "question algérienne " (19541962), Argel, ed. S.N.E.D., 1962. 
mente importante tanto en Argelia como en España: pocos argelinos conocían la lengua española para poder acceder a las fuentes archivísticas y bibliográficas españolas, de igual modo que los historiadores españoles susceptibles de interesarse por la historia de Argelia escasamente conocían el árabe.

En el resumen precedente se ha presentado una panorámica general de los estudios y de las relaciones argelino-españolas que presentó Míkel de Epalza en su obra, publicada en 1976. A partir de esta fecha, es justo añadir que se incrementó el número de estudios, por más que aún quede mucho por investigar y profundizar en este panorama de las relaciones entre Argelia y España.

II. Principales contribuciones de la actividad de Míkel DE EPALZA EN PUBLICACIONES Y CONGRESOS

Míkel de Epalza redactó en Argel la compilación bibliográfica comentada. Merced a esta circunstancia tuvo la oportunidad de tener un acceso fácil a esta rica bibliografía argelina. Por el contrario nos hemos encontrado con grandes problemas para poder acceder a ella y consultarla en España (salvo, quizás, en Madrid).

En el momento de elaborar este balance bibliográfico nos encontramos con muchos problemas para poder acceder a la más reciente bibliografía argelina. Sin embargo fue posible consultar casi todos los volúmenes que fueron editados en francés (y algunos menos en árabe) en nuestra biblioteca del Seminario de Estudios Árabes e Islámicos de la Universidad de Alicante, de las actas de los Séminaires de la Pensée Islamique; y algunos números de la revista $A l$-Asala. Este es uno de los principales problemas de las inves-tigaciones en torno a Argelia: la precariedad y dispersión de las fuentes.

1. El diálogo y el contacto entre los pensadores e investigadores 
europeos y argelinos fue lo que marcó el origen y desarrollo de los debates que se desarrollaron en el marco de los Séminaires de la Pensée Islamique (Multaqayāt ul-fikr il-islāmī), organizados por el Ministerio de Asuntos Religiosos, encontrando en la figura de Mouloud Kassem su principal promotor intelectual.

La participación española se hizo evidente a partir del $6^{\text {eme }}$ Séminaire, en el cual participó Pedro Chalmeta con un estudio sobre los «Facteurs de distorsion idéologique: Religion, natio-

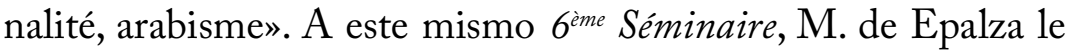
dedicó una recensión en una revista francesa, reseña que fue reproducida a su vez en el no 46-47 de la revista $A l-A$ sala.

Con ocasión del geme Séminaire de la Pensée Islamique celebrado en Bejaïa (Bougie, Bujía) en 1974/1394, se dedicaron numerosas publicaciones, pero en concreto un número especial de la revista $A l-A s a l a$, a los trabajos sobre la historia de esta ciudad argelina, cuyas relaciones con los reinos andalusíes fueron muy frecuentes en la época hammadí, y aún con posterioridad. En este misma línea, Othmane El-Kaak presentó una comunicación sobre «Les bougiotes amazighs, andalous et siciliens et leur rôle éminent dans une civilisation embrassant les deux rives de la Méditerranée pendant quatre siècles» en la que, tras haber revisado la historia de Bujía, enuncia y comenta la presencia de un buen número de andalusíes. En el mismo Seminario el Dr. Saï Chibane ofreció un muy interesante estudio y un resumen de la Guía de oftalmología / Kitāb al-murshid al-kubalayn de Muhammad Ibn Qassūm Ibn Aslam al-Gāfiqī, médico andalusí del siglo VI H./XII J.C. Esta obra recopila y sistematiza todo el conocimiento farmacológico árabe, lo cual le otorga una enorme importancia, y lleva al investigador a calificarla de obra oculística verdaderamente moderna.

En esta misma línea de estudios sobre Al-Andalus, en el $9^{\text {ime }}$ Séminaire, que se celebró en Tlemcen (Tremecén) en 1975 / 1395 M. A. Inán disertó sobre la «Opinión de Istambul y del 
resto del mundo islámico sobre la decadencia de Al-Andalus y los últimos musulmanes», exponiendo la opinión general del mundo islámico acerca de la conquista cristiana, que interpretan como la última de las consecuencias de la decadencia de AlAndalus.

2. De la revista $A l-A$ sala, editada por el Ministerio de Asuntos Religiosos (Wizārat ush-shu'ūn id-dìniyya) deseamos resaltar algunos trabajos publicados durante el período en que Mouloud Kassem fue su principal alma y promotor. Entre las conferencias del 11'me Séminaire la revista Al-Asala publica el trabajo de M. de Epalza titulado «Entre el fanatismo y la islamización», donde estudia la personalidad de Raimon Llull (Raimundus Lulius), religioso mallorquín, filósofo, poeta y un gran autor español en lengua catalana que viajó mucho por Europa, Egipto y el Magreb, dominando la lengua árabe. Formó parte de un franciscanismo que quiso hacer proselitismo entre los musulmanes que no conocían suficientemente el cristianismo. Pero todos los franciscanos no eran tan escrupulosos como el fundador de la orden, puesto que en buen número llegaron al Magreb para propagar el cristianismo por medio del ataque al Profeta y a la religión musulmana. Debido a ello, algunos fueron hechos prisioneros, y luego expulsados a la capital muwahidî, para ser finalmente ejecutados. El ejemplo contrario lo representa otro tipo de franciscanos, como Anselm Turmeda quien, residiendo en Túnez, se convirtió al islam, adoptó el nombre de 'Abd Allāh at-Taryumān, y escribió numerosas obras, en árabe y en catalán.

Sobre otros temas posteriores al siglo XVI, hallamos un panorama prácticamente vacío hasta el momento en que Míkel de Epalza publica algunas de sus investigaciones. En su amplio estudio sobre «Algunos documentos españoles relativos a la historia del Magreb árabe entre los siglos XII-XIII H. / XVIII-XIX J.C.» presenta la documentación relativa a este periodo de 7 ar- 
chivos españoles diferentes. La documentación que presenta trata de: La política española hacia el Magreb; la política diplomática magrebí relativa a algunos otros países; sucesos históricos de importancia en el Magreb; la piratería en el Mediterráneo y sus estipulaciones jurídicas; el comercio mediterráneo en general y especialmente el comercio entre España y los países del Magreb; los desplazamientos de determinados personajes, sobre todo marineros, militares, religiosos y rehenes. Hay tres documentos inéditos tomados del Archivo del Ministerio de Asuntos Extranjeros: diarios del primer cónsul español en Argelia, de 1786-1820; decisión acerca de las circunstancias diplomáticas españolas con el Magreb en 1712; nueve textos sobre las exigencias del Bey de Orán a España, durante su guerra contra el Dey de Argel en 1812.

Míkel de Epalza igualmente ha consagrado un estudio a tres acontecimientos hasta entonces desconocidos de las relaciones entre Annaba (Bône, Bona) y España, presentando tres circunstancias de esta relación: la conquista española de Annaba en el siglo X H/XVI J.C., durante la guerra entre la España de Carlos V y el Norte de África islámico; la emigración de los moriscos a Annaba durante el siglo XI H./XVII J.C.; la crisis surgida entre Argelia y España en el s. XIII H./XIX J.C., causada por un corsario de la isla de Menorca en Annaba.

Y para acabar esta parte dedicada a las publicaciones españolas o sobre temas hispánicos de la revista $A l-A s a l a$ hay que hacer una obligada mención a la entrevista al Dr. Míkel de Epalza sobre «Les minorités musulmanes en Espagne». La situación de las minorías musulmanas era uno de los cinco puntos del $8^{\text {eme. }}$ Séminaire de la Pensée Islamique que tuvo lugar en Bujía en 1974. En esta entrevista, repasó en profundidad y puso en evidencia cómo pueden considerarse cuatro tipos de musulmanes en España atendiendo a su procedencia y ocupaciones (trabajadores manuales, generalmente magrebíes; estudiantes, origina- 
rios sobre todo del Próximo Oriente; profesionales, diplomáticos y con otras profesiones liberales, así como viajeros en paso y turistas). Se expone cómo los problemas de las minorías no son de orden religioso, sino especialmente dificultades y problemas graves de tipo social y económico.

3. Finalmente, citaremos algunos estudios de la revista AthThaqāfa, publicada por el Ministerio de Cultura. Míkel de Epalza publicó en ella «España y la revolución argelina durante el período 1954-1962», época en que España sufrió un aislamiento internacional como consecuencia del apoyo de Franco a Hitler y Moussoulini. Pero los países árabes (Egipto, Jordania e Iraq) durante todo este período prestaron su apoyo a España, como también los países del Tercer Mundo, para poder entrar en la ONU; a cambio España mostró su apoyo a los países árabes, así como a sus intereses, ante la opinión pública y la diplomacia internacional. Tras recoger las opiniones que los periódicos y las radios difundían sobre la revolución argelina, llega a la conclusión de que éstas son muy parciales y limitadamente escasas; concluye que la opinión española sobre la revolución argelina era obligadamente superficial.

III. NuEVAS LÍNEAS DE INVESTIGACIÓN INAUGURADAS POR MíKel DE EPALZA

En los años 80 los trabajos acerca de las épocas medieval y moderna fueron mayoritarios, en especial en los ámbitos de la historia y la literatura. Posteriormente, los investigadores se fijaron y profundizaron más en la época contemporánea. Así, Yahia Bouaziz y Míkel de Epalza estudiaron una nueva documentación, de reciente aparición, sobre el Emir Abdelkáder, en «Correspondances de l'Emir Abdelkader avec l'Espagne et ses gouverneurs militaires à Melilla», así como en «De nouveau sur les relations de l'émir Abdelkader et Espagne et ses gouverneurs 
militaires à Melilla» los dos historiadores publicaron una serie de documentos sobre las relaciones de este personaje con el $\mathrm{Mi}$ nisterio de la Guerra y con la diplomacia española. Estos documentos y misivas muestran cómo el Emir Abdelkáder deseaba que España hiciera una labor de intermediación con Francia, con el fin de que pudiera retornar a Argelia, así como su voluntad de dejar sus corresponsales en Melilla, para que ellos pudieran remitir sus cartas oficiales a sus gobernadores y para que pudieran negociar con ellos. En reciprocidad, el Emir ofrecía sus servicios a España tras haber retornado a Argelia después de su exilio en Damasco. Estas misivas reflejan también las aspiraciones del Emir Abdelkáder por poseer armas y revelan algunos asuntos locales, informando, por ejemplo, de la sumisión al Emir de las tribus situadas en torno a Melilla. Estos últimos aspectos eran muy importantes para España.

Otra obrita contribuye a iluminar la realidad histórica de "Oran et l'Ouest algérien au $18^{\text {ème }}$ siècle d'après le rapport Aramburu». Este informe, publicado y estudiado por Mohamed El Korso y Míkel de Epalza, fue elaborado en 1741 por Joseph d'Aramburu, gobernador militar de la fortaleza de Orán, en esta época dominio español. El interés de este texto reside especialmente en la minuciosa descripción que realiza del interior del país, tanto desde el punto de vista físico, como humano.

Mención especial merece la publicación en un volumen monográfico de la revista Archives Nationales de las Actes du Séminaire International sur les Sources Espagnoles de l'Histoire Algérienne, Seminario organizado por el C.D.S.H. y la Université d'Oran y celebrado entre los días 20 y 22 de abril 1981. Se trata de un excelente ejemplo de eficaz colaboración entre investigadores españoles y argelinos. Publicadas en 1984, estas Actes son un buen balance sobre las fuentes españolas para la historia de Argelia, recogiéndose en ellas las contribuciones de 5 investigadores argelinos, 8 españoles, un tunecino y un italiano. 
Otros estudios han venido a iluminar aspectos bien interesantes, como por ejemplo las relaciones diplomáticas entre Argelia y España en los siglos XVIII y XIX y los tratados de paz firmados entre ambos países. Míkel de Epalza y Maulay Belhamissi han estudiado el tratado de 1786, y Epalza también ha profundizado en las circunstancias políticas de los tratados del siglo XVIII.

Con posterioridad, Míkel de Epalza y Juan Bautista Vilar publicaron una obra de gran relevancia. Sus Planos y mapas hispánicos de Argelia. Siglos XVI-XVIII son la más meritoria y reciente contribución de los españoles a la historiografía de Argelia. En este importante catálogo de cartografía histórica se ofrece una soberbia compilación de material inédito para el estudio de las relaciones entre Argelia y España en la época moderna. En la Presentación hacen una fundada y actualizada revisión de las relaciones hispano-argelinas de los siglos XVI al XVIII, para después presentarnos 497 fichas de mapas, cartas, dibujos y cartas de navegación que van desde el siglo XVI hasta el año 1800, todos ellos existentes en los fondos de los archivos españoles. Predomina el material cartográfico sobre Orán, Merselkevir, Argel y Arzew.

Para acabar, citaremos el estudio de Míkel de Epalza sobre el gran filósofo español del s. XX «Ortega y Gasset: tensión e integración de lo árabe y lo europeo. Introducción a una lectura de su texto sobre Ibn Jaldūn y Melilla», tras revisar su obra, se presentan sus conclusiones acerca de las profundas lagunas que tenía J. Ortega y Gasset sobre el mundo árabe y africano. Este estudio fue un prólogo a la reedición de su ensayo sobre Ibn Jaldūn y Melilla.

REFERENCIAS BIBLIOGRÁFICAS:

- Archives Nationales. Actes du Séminaire International sur les Sources 
Espagnoles de l'Histoire Algérienne. Oran: 20-22 avril 1981, Argel, no 10-11, 1984, 388 pp. Estudios publicados: CHENTOUF, Tayeb: «Les sources locales, étrangères et espagnoles de l'histoire de l'Algérie de XIV ${ }^{\mathrm{e}}$ au XIX ${ }^{\mathrm{e}}$ siècle», pp. 9-32; LÓPEZ GARcíA, Bernabé: «Argelia en la historia del arabismo y del africanismo español (1880-1910)», pp. 33-42; TERKI HASSAINE, Ismet: «Historiographie et nécessité de la recherche historique sur l'Algérie du XIV ${ }^{\mathrm{e}}$ au XIX ${ }^{\mathrm{e}}$ siècle», pp. 43-52; EPALZA, Míkel de: «Plans et cartes hispaniques de l'Algérie», pp. 55-69; GIMÉNEZ, Enrique: «Fuentes para el estudio de las relaciones entre Alicante y la costa norteafricana en el siglo XVII», pp. 71-79; VIDAL, José Juan: «Fuentes mallorquinas para la historia argelina», pp. 81-97; SOLA, Emilio: «Datos cuantificables en la documentación española sobre Argelia (sugerencias para un trabajo de grupo), pp. 99-114; VILAR, Juan Bautista: «Fuentes españolas sobre la Argelia colonial (18301914)», pp. 115-127; NiETO CuMPLIDO, Manuel: «Fuentes documentales españolas para la historia de Argelia», pp. 129-138; SÁNCHEZ DonCEL, Gregorio: «Fuentes españolas para la historia de Orán», pp. 139-277; YACINE, Tassadit: «Présentation de l'oeuvre de F. Zavala», pp. 281-293; MALKI, Nordine; «Le tremblement de terre d'Oran d'octobre 1790 et les tentatives du bey de Mascara pour la libération de cette ville d'après trois documents des Archives Historiques Nationales de Madrid», pp. 295-307; BonO, Salvatore: «Sources hispano-italiennes pour l'histoire algérienne: L'attaque manquée à Alger de 1601», pp. 309-321; EL GAFSI, Abdelhakim: «Note su quelques sources (Archives et Presse relatives à l'histoire de l'Algérie en 1804-1807 et aux espagnols installés en Algérie», pp. 323-340; SoufI, Fouad: «La presse espagnole durant la période coloniale», pp. 341-349; يحيى بوعزيز : 》الجديد في

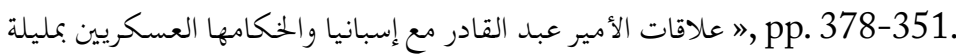

- Bouaziz, Yahia; Epalza, Míkel de: Correspondances de l'Emir Abdelkader avec l'Espagne et ses gouverneurs militaires à Melilla, Argel: ed. Office des Publications Universitaires, 1985, $114+29$ pp.

Reeditado como: Le nouveau sur les relations de l'émir Abdelkader avec 
l'Espagne et ses gouverneurs militaires a Melilla / يحيئ بو عزيز، ميكيل

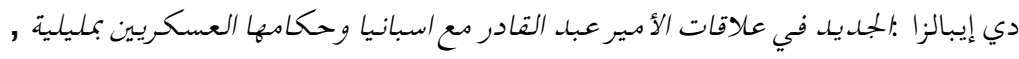
قسنطينة , دار البعث , 1402/1982, 104 + 29 pp.

- [EPALZA, Mikel de]: «Les minorités musulmanes en Espagne» [Entrevista con el Dr. Mikel de Epalza], الاصالة , الجزائر ,وزارة التعليم الأصلي 1394/1974 , والشؤون الدينية , n. 20, pp. 134-138.

بين التعصب و الإِسلامية أو الإسـلام مسن " [EPALZA, Míkel de] ميغال دي ايبالزا خلال بعض الشخصيات في العالم المسيحي (" , الاصالة , الجزائر , و وزارة التعليم الأصلي

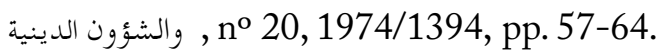

- Epalza, Míkel de: «Algunas consecuencias del tratado de paz hispano-argelino de 1786», Homenaje a Guillermo Guastavino. Miscelánea de estudios en el año de su jubilación como director de la Biblioteca Nacional, Madrid: ed. ANABA, 1974, pp. 443-461.

- EPALZA, Míkel de: Écrits relatifs à l'bistoire de l'Espagne publiés en

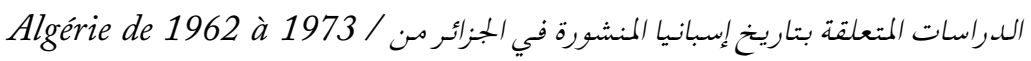
1973 الى Alger: ed. S.N.E.D. (Coll. Publications de la Bibliothèque Nationale, Série Bibliographies et Cathalogues, 3), 1976, 46 + 18 (en árabe) pp.

- Epalza, Míkel de: «El XI Seminario del Pensamiento islámico (Ouargla, Argelia)», Almenara, Madrid: ed. Universidad Autónoma de Madrid, no 10, 1976-1977, pp. 167-179.

حول ثلاثة أحداث غير معروفة من العلاقات " : [EPALZA, Míkel de] ميكال دي ايبالزا -

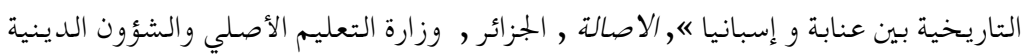
, no 34-35, 1976/1396, pp. 110-121. 
بعرض الوثائق الإِسبانية المتعلقة بتاريخ المغرب ه : ميكال دي ايبالزا -

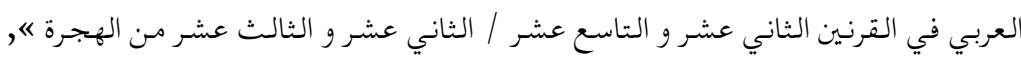

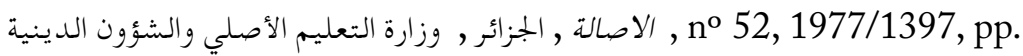
25-30.

- EpalzA, Míkel de: «Compte-rendu sur le livre de J. B. Vilar [Emigración española en Argelia (1830-1900)]", Bulletin de la Société Géographique et d'Archéologie d'Oran, Orán, années 1977-1978, pp. 55-59.

- Epalza, Míkel de: «Revue d’Histoire Maghrébine (Tunis), no 1314 (1979). Volume spécial Méthodologie et Sources d'Histoire du Maghreb. Note sur les forteresses hispaniques au Maghreb», Bulletin de la Société Géographique et d'Archéologie d'Oran, Orán, année 1979, pp. 91-95.

- EpalZa, Míkel de: «Fuentes españolas de historia de Argelia (siglos XVI-XVIII)", Anales de la Universidad de Alicante. Historia Moderna, Alicante: ed. Universidad de Alicante, no 1, 1981, pp. 141149.

- EPALZA, Míkel de: «Intereses árabes e intereses españoles en las paces hispano-musulmanas del siglo XVIII», Anales de Historia Contemporánea, Murcia: ed. Universidad de Murcia, no 1, 1982, pp. 717

إسبانيا والثورة الجزائرية «, الثقافة , الجزائر , « [EPALZA, Míkel de] ميغال دي ايبالزا -

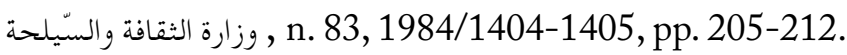

الملتقئ الحادي عشر للفكر الإِسلامي ( ورقلة ه : ميغيل دي ايبالزا -

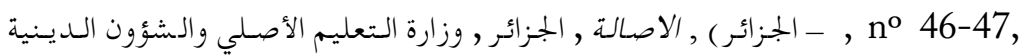
1977/1397, pp. 51-62. 
- Epalza, Míkel de: «Ortega y Gasset: tensión e integración de lo árabe y lo europeo», Mundo Árabe / Mundo Hispánico: Creatividad e Historia. Homenaje a Marcelino Villegas, Madrid: ed. I.C.M.A. (Col. “Awraq", no 1), 1994, pp. 43-52.

- Epalza, Míkel de; VILAR, Juan Bautista: Planos y mapas hispánicos de Argelia. Siglos XVI-XVIII / Plans et cartes hispaniques de l'Algérie, $X V^{\text {eme }}-X V I I^{\text {eme }}$ siècles, Madrid, ed. Ministerio de Asuntos Exteriores, Generalitat Valenciana, Instituto "Juan Gil Albert", Facultad Letras de Murcia, 1988, 403 pp.

- El Korso, Mohamed; Epalza, Míkel de: Oran et l'Ouest algérien

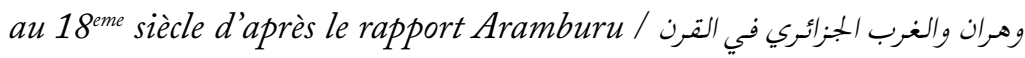
18 , Argel: ed. Bibliothèque Nationale (Coll. Publications de la Bibliothèque Nationale, Série Notes et Documents, 3), 1978, 166 pp. (15 en árabe). 